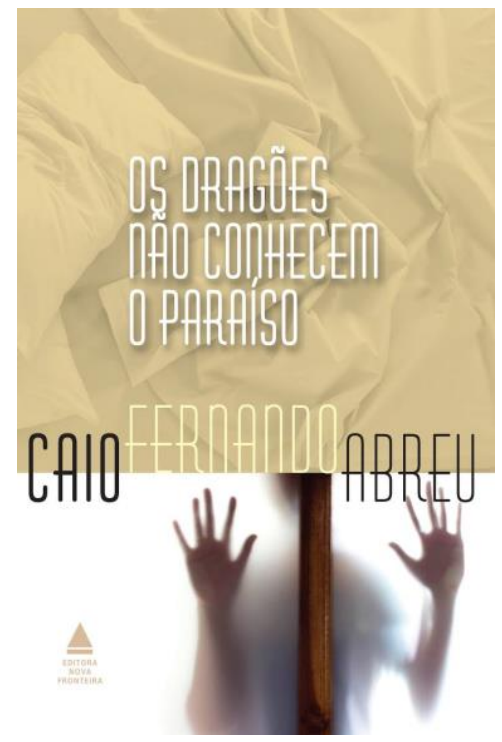

\title{
Os Dragões de Caio Fernando Abreu: literatura engajada e a questão do Outro
} The Dragons of Caio Fernando Abreu: engaged literature and the question of the Other

\begin{abstract}
Nícollas Cayann ${ }^{1}$
Anselmo Peres Alós ${ }^{2}$

Resumo:

Baseada majoritariamente nos conceitos de literatura engajada (SARTRE, 1948), a presente resenha trabalha a ideia de escrita engajada (social e política) em Caio Fernando Abreu, na coletânea de contos Os dragões não conhecem o paraíso, de 1988. A resenha busca estabelecer um diálogo entre a obra mencionada e a literatura engajada de Caio Fernando Abreu. Utilizando análise documental e revisão bibliográfica em seus cernes conceituais, teóricos e históricos, partindo de dados secundários e uma abordagem qualitativa, a resenha analisa o texto enfocando principalmente para a questão da alteridade e da presença dos fatores autobiográficos nas escolhas estética estabelecidas pelo autor em alguns dos treze contos que compõe o livro. A resenha trata ainda, de forma secundária, a questão da intertextualidade e das referências culturais que, neste livro em específico, são diversas e capazes de ampliar a compreensão do texto.
\end{abstract}

Palavras-chave: Caio Fernando Abreu, Os Dragões não conhecem o paraíso, literatura engajada.

\begin{abstract}
:
Based mostly on the concepts of engaged literature (SARTRE, 1948), this review works on the idea of engaged writing (social and political) in Caio Fernando Abreu's Os dragões não conhecem o paraíso (first published in 1988). The review aims at establishing a dialogue between the mentioned work and the engaged literature of Caio Fernando Abreu. Using documentary analysis and bibliographic review in its conceptual, theoretical and historical contexts, based on secondary data and a qualitative approach, the review analyzes the text focusing mainly on the issue of alterity and the presence of autobiographical factors in aesthetic choices established by the author in some of the thirteen short stories that make up the above-mentioned book. The review also deals, in a secondary way, with the question of intertextuality and the cultural references that, in this particular book, are diverse and capable of broadening the understanding of the text.
\end{abstract}

Keywords: Caio Fernando Abreu, Os Dragões não conhecem o paraíso, engaged literature.

\footnotetext{
${ }^{1}$ Bacharel em Relações Internacionais pela Universidade Federal de Pelotas, Mestre pelo Programa de Pós-Graduação em Literatura Comparada da Universidade Federal da Integração Latino-Americana. Doutorando em Estudos Literários na Universidade Federal de Santa Maria. E-mail: nicollascayann@gmail.com. ORCID: https://orcid.org/0000-0001-9493-1102

${ }^{2}$ Anselmo Peres Alós é Professor Adjunto IV na Universidade Federal de Santa Maria, UFSM. Docente Permanente do PPG-Letras, da mesma instituição, e Bolsista de Produtividade em Pesquisa do CNPq.. Email: anselmoperesalos@gmail.com. ORCID: https://orcid.org/0000-0003-2062-2096
} 
Caio Fernando Abreu foi jornalista e dramaturgo, escritor brasileiro nascido em terras sul-rio-grandenses. Sua obra dialoga com o período da contemporaneidade, sua escrita trata de morte, dos medos, do sexo, da erotização, e a pena do autor tem um espaço especial para o tema da solidão.

Caio Fernando Abreu possuía muita afinidade com a obra do contista dinamarquês Hans Christian Andersen, e isso fica evidente no título de alguns contos como, por exemplo, "Os sapatinhos vermelhos". O autor dedicou-se majoritariamente ao conto como seu gênero literário preferido. $\mathrm{O}$ autor também era ligado ao cenário da cultura pop (possivelmente pelo entrelaçamento da cultura pop e do movimento gay ao longo das décadas de 1970 e 1980) incluindo referências que vão de Audrey Hepburne (atriz britânica) a Sapatinhos vermelhos (musical de 1948). A coletânea de contos "Os dragões não conhecem o paraíso está repleta de referências musicais (como às músicas de Cazuza - importante ícone na história gay e na história dos vitimados pelo HIV no Brasil).

Os dragões não conhecem o paraíso, publicado em 1988, pela Companhia das Letras, trouxe a Caio um sucesso que o próprio autor não previra. Foi com esse livro de contos - ou romance-móbile, como próprio autor caracterizava o livro -, que Caio teve sua primeira obra traduzida e publicada em língua estrangeira, trabalho atencioso e polido da editora inglesa Boulevard, para uma coleção composta de autores latinoamericanos.

O livro é composto por treze contos com diversas tramas, porém todas se entrelaçam na temática da alteridade. O conflito da alteridade e o enfrentamento com o "outro" se faz através da linguagem criativa de Caio Fernando Abreu. O autor utiliza a dor e o sofrimento, assim como a solidão, quase como personagens das tramas expostas nos treze contos. Embora seja um livro curto, de 157 páginas, é uma complexa colcha de retalhos que Caio Fernando Abreu tece em tom intimista, aproximando o leitor dessas histórias singulares - e muitas vezes, na visão geral, marginalizadas - de seus personagens.

Além da alteridade, os treze contos relacionam-se por tratar de temas como o amor, a erotização e a solidão. Alguns personagens - homens e mulheres de meia-idade, homossexuais, bêbados - são os dragões (aqueles cujas narrativas são postas à margem da sociedade) na busca da plenitude do erotismo, ou do desfecho da solidão. Embora o autor indique com suas palavras que o livro trata do amor, o texto seria melhor 
compreendido se fosse entendido pela questão da incompletude do amor que vivem os dragões/personagens de Caio em Os dragões não conhecem o paraíso.

Uma gama de diversas experiências envolvendo o tema da sexualidade compõe a trama que permeia os diferentes contos de Os dragões não conhecem o paraíso. Em "Linda, uma história horrível", o autor trata da questão da doença. De acordo com Caio Fernando Abreu, em entrevista no ano de 1995, esse conto foi a primeira história brasileira sobre o tema da doença; em "Pequeno monstro", Caio trata das questões de intimidade de primos, de iniciação sexual de meninos e da relação dessas práticas com a homossexualidade e com as questões de alteridade na construção das identidades e dos aspectos provisórios e flexíveis desses processos; em "Dama da Noite", é tratado o caso de uma mulher libertária que inclusive pode ser "lida" como cis- ou trans-. Os personagens desses contos de Caio Fernando Abreu são transgressores, e é através da transgressão que se dá espaço à voz dos marginalizados.

A obra de Caio terminou sendo reconhecida como exemplar narrativo representativo daquilo que se entende por literatura brasileira contemporânea. Junto ao crescimento dos estudos queer no Brasil, e junto à ascensão dos aspectos políticosociais nas manifestações culturais e nas leituras de mundo - forjados já nos anos 1930, mas fortificados no cerne da pós-modernidade - críticos e estudiosos da fortuna crítica que rodeia a escrita de Caio têm prestado relevante atenção à temática da homossexualidade. Entender a expressão dos valores políticos e sociais transmitidos pelo autor torna a leitura dos contos um ato mais elaborado. A constante presença na escrita de Caio das questões de liberdade sexual e da permanência do tema da homossexualidade na construção da literatura brasileira contemporânea têm um papel fundamental na compreensão do estilo estético utilizado por Caio Fernando Abreu. Estilo esse que se mistura com as temáticas político-sociais abordadas pelo autor, fazendo-se passível de ser analisado como literatura engajada.

A ideia de literatura é plural e permite diferentes abordagens, e os aspectos pósestruturalistas das análises literárias permitem um enfoque mais amplo naquilo que tange as questões sociais e políticas que compõe as obras literárias (EAGLETON, 1983). O termo literatura engajada surgiu nos textos de Sartre na revista Les Temps Modernes, em 1945, em Paris. Para Sartre, a ideia de literatura engajada está ligada ao compromisso que a literatura tem com as vozes abafadas nas narrativas hegemônicas. Segundo o filósofo, a literatura só é literatura quando consegue desempenhar sua função social, isto é, ser uma literatura que promove reflexão sobre as realidades político- 
sociais nas quais os autores estão também incluídos é refletir sobre os tempos em que se vive. Sartre ainda questiona: o que é escrever? Por que escrever? Para quem se escreve?

Faz-se necessário indagar qual aspecto o autor engajado escolhe trabalhar, e como proposta estética, a literatura engajada é feita de tal forma que os propósitos estéticos e político-sociais são inseparáveis. No caso de Caio Fernando Abreu, existiu uma gradativa incorporação do tema da homossexualidade em sua produção literária.

A existência dos personagens transgressores sempre esteve presente na obra de Caio Fernando Abreu, mas na medida em que o autor se expunha como homossexual, também se expunham seus personagens. No livro Os dragões não conhecem o paraíso, surge a presença de uma outra temática, que também estava corporificada na vida de Caio: a doença.

Ao se assumir publicamente como escritor soropositivo, Caio Fernando Abreu foi abrindo espaço na sua obra e na sua narrativa pessoal e fictícia para tratar do tema. $\mathrm{O}$ autor, em Os dragões não conhecem o paraíso, traz o tema do HIV e da AIDS de uma forma estética muito bem elaborada, demonstrando o aspecto predatório da doença no conto "Linda, uma história horrível". No conto, a doença vai, através de aspectos estéticos do texto, cercando o protagonista como um predador cerca sua presa.

$\mathrm{Na}$ época em que Caio Fernando Abreu tornou público seu status sorológico, era precisamente a época do boom epidêmico do HIV e da AIDS no âmbito nacional e internacional. Tratar dessas questões não é apenas uma forma de luta e de literatura engajada, mas, no caso de Caio, é também um fator autobiográfico (PORTO e PORTO, 2004). Deve-se ainda mencionar que não é por acaso que o protagonista de "Linda, uma história horrível" tem quarenta e poucos anos, assim como a protagonista de "Os sapatinhos vermelhos". À medida que a doença ganha espaço na vida do autor, e que a homossexualidade, no cerne de toda essa questão, envolve a obra do autor, Caio Fernando Abreu trabalha as questões de alteridade através do outro gay de forma autobiográfica. Os primos, em "Pequeno monstro", os personagens de 40 e poucos anos, o homem que vive com a doença, podem todos ser lidos como personas do autor.

Além do aspecto estético engajado, e autobiográfico, é necessário falar ainda da sonoridade da narrativa de Caio Fernando Abreu. A obra de Caio é marcada por aspectos poéticos da linguagem. Em Os dragões não conhecem o paraíso, o autor utiliza de um recurso curioso: referências ao universo musical popular, onde o rock e a MPB figuram com destaque (SANTANA, 2014). 
Caio Fernando Abreu indica, no cabeçalho de cada um dos treze contos, músicas para embalar a leitura de sua obra. Ao acrescentar essas músicas como pano de fundo para os contos, o autor adiciona uma nova poética, novos ruídos, novos ritmos de leitura aos seus contos. Como exemplo, cabe citar a menção à canção Só as mães são felizes, de Cazuza, e a sugestão de ler o conto "Mel \& girassóis" ao som de Nara Leão.

A intertextualidade é um aspecto que sempre esteve presente nos processos literários. Contudo, na modernidade e na pós-modernidade, existe uma atenção maior aos aspectos intertextuais da literatura. Nesse sentido, pode-se dizer que Caio Fernando Abreu foi um precursor da prosa que supervaloriza o potencial da intertextualidade.

O processo de criação da prosa que faz alusão a obras cinematográficas, outros livros, outros contos, músicas e poemas é uma característica recorrente em Caio Fernando Abreu e um forte traço literário em Os dragões não conhecem o paraíso, contendo inclusive referências a outros textos de Caio, como é o caso de "Saudades de Audrey Hepburn (a nova história embaçada)", referência ao conto de Morangos mofados intitulado "Os Companheiros (uma história embaçada)".

Caio Fernando Abreu foi um escritor gaúcho reconhecido internacionalmente. A obra de Caio é marcada pela questão do outro gay, e essas marcas de alteridade ficam bastante visíveis em Os dragões não conhecem o paraíso. O ato de ficcionalizar de Caio Fernando Abreu trouxe para os leitores brasileiros não apenas a temática do Outro homossexual, mas também colocou na rota literária da produção moderna da literatura brasileira o homossexual com o retrato tanto do HIV quanto da AIDS.

\section{REFERÊNCIAS}

ABREU, Caio Fernando. Morangos mofados. Rio de Janeiro: Agir, 2005 [1982]. 160p.

ABREU, Caio Fernando. Os dragões não conhecem o paraíso. São Paulo: Companhia das Letras, 1988. 157p.

ABREU, Caio Fernando. Dragons. Londres: Boulevard books, 1990. 149 p.

EAGLETON. Terry. Teoria da Literatura: uma introdução. 6. ed. São Paulo: Martins Fontes, 2006 [1983], 400p.

PORTO, Ana Paula e PORTO, Luana. Caio Fernando Abreu e uma trajetória de crítica social. Revista Letras. Curitiba, n. 62, p. 61-77, jan.-abr. 2004. Disponível em: <http://www.letras.ufpr.br/documentos/pdf_revistas/porto.pdf>. Acesso em: $27 \mathrm{dez}$. 2017.

SANTANA, Iara. A música em contos de Caio Fernando Abreu: inventário musical de Os dragões não conhecem o paraíso e Dragons..., sua tradução para o inglês. Dissertação de Mestrado (Letras - Literatura). São Paulo, Universidade de São Paulo, 
2014, 167p. Disponível em: <http://www.teses.usp.br/teses/disponiveis/8/8147/tde01122014-123954/publico/2014_LaraSoutoSantana_VCorr.pdf>. Acesso em: 18 out. 2017.

SARTRE, Jean-Paul. Preséntation des Temps Modernes. Les Temps Modernes, Paris, 1945, p. 4 - 17.

SARTRE, Jean-Paul. Qu'est-ce que la littérature. Paris:Gallimard, 1948, 384 p.

Data de Recebimento: 27/06/2017

Data de Aprovação: 02/10/2017 


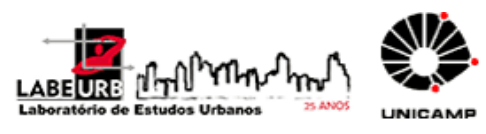

\section{Para citar essa obra:}

CAYANN, NICOLlAS; ALÒS, Anselmo Peres. Os Dragões de Caio Fernando Abreu: literatura engajada e a questão do Outro. In: RUA [online]. $n^{\circ}$. 24. Volume 1 - p. 305-310 - e-ISSN 21799911 - junho/2018. Consultada no Portal Labeurb - Revista do Laboratório de Estudos Urbanos do Núcleo de Desenvolvimento da Criatividade.

http://www.labeurb.unicamp.br/rua/

Capa: Capa do livro "Os dragões não conhecem o paraíso"

\section{Laboratório de Estudos Urbanos - LABEURB}

Núcleo de Desenvolvimento da Criatividade - NUDECRI

Universidade Estadual de Campinas - UNICAMP

http://www.labeurb.unicamp.br/

\section{Endereço:}

LABEURB - LABORATÓRIO DE ESTUDOS URBANOS

UNICAMP/COCEN / NUDECRI

CAIXA POSTAL 6166

Campinas/SP - Brasil

CEP 13083-892

Fone/ Fax: (19) 3521-7900

Contato: http://www.labeurb.unicamp.br/contato 